\title{
Anxiety is Prevailing in Non-Cardiac Chest Pain Subjects, while Somatisation is Not A Comparative Study in the Emergency Department \\ Matteo Balestrieri ${ }^{1 *}$, Miriam Isola ${ }^{2}$, Fabrizio Gangi ${ }^{3}$, Rodolfo Sbrojavacca ${ }^{4}$ and PResT-ED ${ }^{5 *}$
}

${ }^{1}$ Psychiatric Clinic, Department of Experimental and Clinical Medical Sciences, University of Udine, Udine, Italy

${ }^{2}$ Department of Medical and Biological Sciences, Section of Statistics, University of Udine, Udine, Italy

${ }^{3}$ Primary Care Clinic, Udine, Italy

${ }^{4}$ Emergency Department, Azienda Ospedaliero Universitaria, Udine, Italy

${ }^{5}$ PResT-ED (Psychiatric Resident Team in the Emergency Unit), Udine, Italy

"Team members: Taboga Flavio, Zuanon Sophia, Ragogna Maria, Canalaz Francesca, Meduri Martina, Pellizzari Jessica, Lestani Alessia, Zamboli Rosita, Tam Tatiana, Baglivo Valentina, De Caneva Erica, Fiorindo Francesca, Cecchetto Filippo, Gerlin Diego

\section{Abstract}

Objective: The main purpose of this study was to verify if non-cardiac chest pain (NCCP) subjects recruited in an Emergency Department were more anxious, depressive or burdened by somatoform symptoms as compared with cardiac chest pain (CCP) subjects, and with subjects without chest pain (WOCP).

Methods: We included patients with chest pain not attributable to a gastro-oesophageal reflux disorder. NCCP subjects were negative at ECG examination and at troponin test at baseline and after three months. A number of instruments were administered, measuring anxiety and depression (HADS), somatisation (somatisation scale of SCL90, TAS-20), and the health-related QoL (SF-12), along with other scales measuring the social and experiential profile.

Results: We recruited 435 subjects (of which NCCP were 44.8\%) in the Emergency Department, while other 147 subjects were recruited in a primary care clinic. The logistic regression showed that the levels of HADS anxiety in the three groups were dissimilar, even when adjusted for confounding variables: taking NCCP as reference category, adjusted ORs were 0.64 for CCP (IC95\% $0.42-0.96$ ) and 0.23 for WOCP (IC95\% $0.13-0.40)$. When considering the somatisation construct, CCP and NCCP subjects reported similar somatic symptom complaints, higher than WOCP subjects. Moreover, even if NCCP subjects showed higher TAS-20 scores than WOCP subjects, these scores were below the range of a possible alexithymia. As for the physical health-related QoL (SF-12, subscale PCS-12), regression analyses showed that the PCS-12 mean score of NCCP was higher than that of CCP ( $B-2.31$; IC95\% -4.14 to -0.48$)$ and lower than that of WOCP ( 2.24 ; IC95\% $0.12-4.37$ ).

Conclusion: NCCP subjects are characterised from an elevated anxiety, together with a better physical well-being, when compared with subjects who have a cardiac failure. The somatisation construct seems less useful to distinguish NCCP from CCP subjects. Consequently, anxiety should be the major target of our mental-health intervention when treating subjects with chest pain.

Keywords: Non-cardiac chest pain; Coronary heart disease; Chest pain, Anxiety; HADS; SF-12; Somatisation; Alexithymia

\section{Introduction}

Chest pain is one of the most frequent causes of consultation in health services [1]. Only in a third of cases the cause of chest pain symptoms is of organic nature, particularly ischemic heart pain and pain from gastro-oesophageal disease, while in more than two thirds of cases the diagnosis is not defined [2]. Thus, the need to make a differential diagnosis between organic and functional nature of the pain symptoms remains one of the main targets of the investigation in the Emergency Department, and the assessment of the mental health profile of these patients is an important part of this process.

In doing so, two approaches can be taken in consideration. The first one focuses on the clinical presentation and refers in particular to the presence of anxiety and/or depression symptoms, the second one refers to the somatisation construct and takes in consideration the underlying mechanisms that converts the subjective sufferance in somatic symptoms. According to Lipowski, the somatisation is "the tendency to experience and communicate somatic distress and symptoms unaccounted for by pathological findings, to attribute them to physical illness, and to seek medical help for them" [3]. A number of risk factors have been associated with somatisation: some personality traits, an alexithymic profile, the role of traumatic experiences during childhood or in the recent past, the pattern of attachment with family members, a heightened awareness of normal bodily sensations, a learned cognitive tendency to interpret physical symptoms as indicative of medical illness. As a matter of fact, there is no a priori demonstration that one approach is better than the other, while no study actually attempted to compare the two approaches. A relatively recent survey on chest pain in the Emergency Department concluded that non-cardiac chest pain (NCCP) subjects have similar levels of anxiety and depression of patients who receive a cardiac diagnosis, but worse levels than healthy controls [4]. To note, anxiety and depression were assessed in nine studies, but only few of these supplemented the HADS scale with a psychiatric evaluation, in order to evaluate the prevalence of panic disorder. Moreover, less than a half of the studies compared NCCP with patients with a coronary artery disease and only two study compared NCCP with a control group.

*Corresponding author: Matteo Balestrieri, Psychiatric Clinic, Department of Experimental and Clinical Medical Sciences, University of Udine, Udine, Italy, Tel: 0432559284; Fax: 0432559188 E-mail: matteo.balestrieri57@gmail.com

Received July 13, 2016; Accepted August 02, 2016; Published August 05, 2016

Citation: Balestrieri M, Isola M, Gangi F, Sbrojavacca R, PResT-ED (2016) Anxiety is Prevailing in Non-Cardiac Chest Pain Subjects, while Somatisation is Not A Comparative Study in the Emergency Department. J Depress Anxiety 5: 243. doi: 10.4172/2167-1044.1000243

Copyright: () 2016 Balestrieri M, et al. This is an open-access article distributed under the terms of the Creative Commons Attribution License, which permits unrestricted use, distribution, and reproduction in any medium, provided the original author and source are credited. 
Citation: Balestrieri M, Isola M, Gangi F, Sbrojavacca R, PResT-ED (2016) Anxiety is Prevailing in Non-Cardiac Chest Pain Subjects, while Somatisation is Not A Comparative Study in the Emergency Department. J Depress Anxiety 5: 243. doi: 10.4172/2167-1044.1000243

When considering the somatisation approach, we may refer to the systematic review carried out by Crombez et al. [5], which analysed the concept of somatisation in empirical studies of pain. This review was able to identify 116 studies, most of which used the SCL-90 scale. Of these, only four studies explicitly investigated whether the somatisation symptoms were unaccounted for by organic findings, and none was focused on cardiac or chest pain. The results were inconclusive because of the poor quality of the studies identified.

In synthesis, so far the literature is poorly characterised by comprehensive studies that compared NCCP and cardiac chest pain (CCP) subjects for the presence of anxiety/depression on one side and somatisation on the other side. The main aims of this study were: to characterize patients with NCCP in terms of anxious, depressive and somatoform symptoms, to compare these symptoms with those of patients with CCP subjects and with subjects without chest pain (WOCP) recruited in a primary care clinic.

Our main hypotheses were that a) NCCP subjects would be more anxious and/or depressed than CCP, and even more so than WOCP subjects, and that b) NCCP subjects would be more burdened by somatisation symptoms than the other two groups of subjects. Secondary hypotheses were that c) patients with NCCP would report a history of childhood adversity, as a possible pathogenic factor of somatic pain, and that d) familial and social interactions of NCCP subjects would be worse, as they could be psychologically related to functional pain symptoms, either as causative factors or as consequences of the symptoms themselves.

\section{Methods}

This is a cross-sectional, comparative study. The trial was conducted in the Department of Emergency Medicine of the Academic Hospital in Udine, Italy. The study aimed to recruit patients aged 18 years or more, who contacted the Emergency Department (ED) of the Academic Hospital of Udine with symptoms of chest pain. Individuals were recruited with a triage in the ED that established if they were suffering from a chest pain. These subjects were interviewed either directly at their first contact or at the subsequent regime of observation available in the ED. The control group (WOCP) was recruited by identifying subjects that dropped consecutively into the primary care clinic of one general practitioner in Udine, at exclusion of those who complained for a chest pain. The subjects that resulted positive at MINI for a Panic Disorder were excluded from the analyses. The presence of a gastro-oesophageal reflux disorder was investigated by means of a clinical examination and, if ascertained, it was reason for exclusion of the patients from our study.

Each patient signed a regular consensus to the examination, after adequate information was given. The Ethics Committee of the Academic Hospital approved the study. After medical evaluation, we included in the NCCP group all patients who had no symptoms suggestive for angina and were negative at serial ECG examination and at troponin tests performed according to Chest Pain Evaluation Protocol of ED. The subjects who were positive at the two exams were included in the CCP group. After 3 months from the recruitment of each subject, we verified the diagnosis of NCCP, by consulting the databases of the ED. This check was aimed at excluding from the NCCP group those who at subsequent visits at the ED had a diagnosis of acute coronary syndrome or had a positive stress test. The clinical and therapeutic management of the patients was left to the ED doctors, as per normal clinical practice.

\section{Instruments}

We assessed the three groups of patients with a number of instruments. MINI 5.0.1. This is a short structured diagnostic interview, jointly developed by psychiatrists and clinicians in the United States and Europe, for DSM-IV and ICD-10 psychiatric disorders. It was designed to meet the need for a short but accurate, structured psychiatric interview for multi-centre clinical trials and epidemiology studies $[6,7]$. We used only module $\mathrm{E}$, which focuses on the presence of panic, to exclude patients suffering from panic disorder in the last month.

The SCL-90 (Symptom Checklist-90) is a brief questionnaire designed to evaluate a broad range of psychological problems and symptoms of psychopathology [8]. We used its 12-item somatization scale, which measures distress arising from bodily perceptions. Complaints focused on cardiovascular, gastrointestinal, respiratory, and other systems with autonomic mediation are included.

The HADS is a self-report scale developed to assess the severity of depression and anxiety in primary care and in general hospital settings. The HADS has been used in several surveys worldwide [9]. In accordance with the literature, we considered non-cases of anxiety and/or depression subjects scoring below 8 in the respective subscales of HADS.

SF-12 (Short Form Health Survey-12): The SF-36 was developed for the Medical Outcomes Study, a multi-year study of patients with chronic conditions. The successive refinement of the instrument produced the SF-12 [10]. The SF-12 uses just 12 questions to measure functional health and well-being from the patient's point of view. The SF-12 covers 8 health-related quality of life (QoL) domains. From these domains, summary scores for the physical component (PCS-12) and for the mental component (MCS-12) can be computed.

VAS. The pain Visual Analogue Scale is a one-dimensional measure of pain intensity, which has been widely used in diverse adult populations [11].

TAS-20 (Toronto Alexithymia Scale): This is a 20-item, 5-point forced-choice scale estimating the difficulty in identifying and describing feelings and the presence of externally oriented thinking [12]. The TAS-20 yields three factors (TAS-1: difficulty identifying feelings, TAS-2: difficulty describing feelings, and TAS-3: externally oriented thinking), which are congruent with the salient facets of the construct.

ISSI (Interview Schedule for Social Interaction): This is a 12item interview schedule, which measures the availability and perceived adequacy of a wide range of social contacts and relationships [13]. The instrument yields two scales describing availability of deep emotional relationships or "attachment" on one hand, and availability of more peripheral contacts of social networks and "social integration" on the other. This instrument was used in populations of coronary heart disease subjects $[14,15]$.

Family APGAR Questionnaire: This questionnaire assesses the family member's perception of family functioning by examining his/ her satisfaction with family relationships [16]. The measure consists of five parameters of family functioning: Adaptability, Partnership, Growth, Affection, and Resolve. The response options were designed to describe frequency of feeling satisfied with each parameter on a 3-point scale ranging from 0 (hardly ever) to 2 (almost always). In this study we added two more questions asking the presence of coercive methods and/or traumatic sexual experiences during infancy.

Life Events Stress Test: This is a well-known list of 43 stressful life events that can contribute to illness [17]. 
Citation: Balestrieri M, Isola M, Gangi F, Sbrojavacca R, PResT-ED (2016) Anxiety is Prevailing in Non-Cardiac Chest Pain Subjects, while Somatisation is Not A Comparative Study in the Emergency Department. J Depress Anxiety 5: 243. doi: 10.4172/2167-1044.1000243

\section{Statistics}

The prevalence of NCCP was estimated with a 95\% exact (ClopperPearson) confidence interval.

Characteristics of the study population were described using median and range for continuous variables and frequencies and percentages for categorical variables.

Data were tested for normal distribution using the Shapiro-Wilk test. Kruskal-Wallis or Mann-Whitney test were used to compare continuous variables among groups and between groups respectively. For categorical variables, cross-tabulations were generated, and chi-square or Fisher exact test was used to compare distributions. Bonferroni correction was applied for multiple comparisons.

Logistic regression or linear regression analyses, as appropriate, were used to explore if the differences between NCCP and CCP in the outcome measures were confirmed after adjusting for sociodemographic variables and BMI.

\section{Results}

The period of recruitment lasted 34 months. At its end, the total number of patients selected in the ED was of 435 subjects, while other 147 subjects were recruited in the primary care clinic. The NCCP subjects accounted for $44.8 \%$ (IC95\% $40 \%-49 \%$ ) of the ED patients.

Table 1 shows that median age were different in the three groups, as well as marital and occupational status. As far as other health measures are concerned, only BMI was different (the WOCP subjects had the lowest levels) while smoking habits, use of psychotropic drugs, family support, traumatic experiences in childhood, social interactions and life events did not differ among the groups.

Table 2 shows that the presence of pain, as measured with VAS scale, was necessarily lower in WOCP subjects, without differences between the two hospital groups.

On the other hand, the distribution of HADS scores showed that anxiety was different in the three groups, while depression was not: anxiety was at the highest levels in NCCP subjects, and at the lowest levels in WOCP subjects (Figure 1). The logistic regression confirmed that the levels of HADS anxiety in the three groups were dissimilar, even when adjusted for variables that at baseline were different among the groups: socio-demographic variables (age, gender, marital status, occupational status) and BMI. Taking NCCP as reference category, adjusted ORs were for CCP 0.64 (IC95\% 0.42 - 0.96) and for WOCP 0.23 (IC95\% $0.13-0.40)$.

When considering the SCL-90 somatization scale, CCP and NCCP subjects obtained similar scores, but both of them had more symptom complaints than WOCP subjects. Moreover, alexithymia was not different between the two hospital groups, even though NCCP subjects showed higher TAS scores than WOCP subjects in subscales 1, 3 and in the total scale.

As far as the two components of SF-12 are concerned, only PCS-12 was different in the three groups, with CCP subjects showing a worse physical health-related QoL than both other two groups. Regression analyses confirmed that the PCS-12 scores in the three groups were

\begin{tabular}{|c|c|c|c|c|c|}
\hline & NCCP & CCP & WOCP & Total (\%) & Sign \\
\hline Total & 195 & 240 & 147 & 582 & \\
\hline $\begin{array}{l}\text { Gender } \\
\text { Male } \\
\text { Female }\end{array}$ & $\begin{array}{c}126(64.6) \\
69(35.6)\end{array}$ & $\begin{array}{l}135(56.2) \\
105(43.8)\end{array}$ & $\begin{array}{l}58(39.5) \\
89(60.5)\end{array}$ & $\begin{array}{l}319(54.8) \\
263(45.2)\end{array}$ & $\begin{array}{c}X^{2}=21.76 ; d f=2 \\
p<0.001\end{array}$ \\
\hline Age (median, range) & $58.0(24-87)$ & $63.0(19-90)$ & $55.0(18-85)$ & $58.4(\mathrm{SD} 14.6)$ & $\begin{array}{c}{ }^{*} X^{2}=26.9 ; d f=2 \\
p=0.001\end{array}$ \\
\hline $\begin{array}{l}\text { Marital status } \\
\text { Single } \\
\text { Married/living together } \\
\text { Divorced/separated/widowed }\end{array}$ & $\begin{array}{l}23(11.8) \\
143(73.3) \\
29(14.9)\end{array}$ & $\begin{array}{c}21(8.7) \\
173(72.1) \\
46(19.2)\end{array}$ & $\begin{array}{l}29(19.7) \\
96(65.3) \\
22(15.0)\end{array}$ & $\begin{array}{c}73(12.5) \\
412(70.8) \\
97(16.7)\end{array}$ & $\begin{array}{c}X^{2}=11.28 ; d f=4 \\
P=0.024\end{array}$ \\
\hline $\begin{array}{l}\text { Occupational status } \\
\text { Occupied } \\
\text { Retired } \\
\text { Other }\end{array}$ & $\begin{array}{l}99(50.8) \\
76(39.0) \\
20(10.2)\end{array}$ & $\begin{array}{c}86(35.8) \\
116(48.3) \\
38(15.8)\end{array}$ & $\begin{array}{l}70(47.6) \\
53(36.1) \\
24(16.3)\end{array}$ & $\begin{array}{l}255(43.8) \\
245(42.1) \\
82(14.1)\end{array}$ & $\begin{array}{c}X^{2}=13.14 \\
D f=4 \\
p=0.011\end{array}$ \\
\hline BMI (median) & $26.6(18.5-42.9)$ & $26.6(16.6-54.0)$ & $24.2(16.4-48.4)$ & $25.9(16.4-54.0)$ & $\begin{array}{c}\mathrm{X}^{2}=30.83 ; \mathrm{df}=2 \\
P=0.0001\end{array}$ \\
\hline $\begin{array}{l}\text { Smoking } \\
\text { No } \\
\text { Yes }\end{array}$ & $\begin{array}{c}164(84.1) \\
31(15.9)\end{array}$ & $\begin{array}{c}207(86.3) \\
33(13.7)\end{array}$ & $\begin{array}{l}120(81.6) \\
27(18.4)\end{array}$ & $\begin{array}{c}491(84.4) \\
91(15.6)\end{array}$ & $\begin{array}{c}X^{2}=1.48 ; d f=2 \\
P=0.475\end{array}$ \\
\hline $\begin{array}{l}\text { Psychotropic drugs } \\
\text { No } \\
\text { Analgesic } \\
\text { Psychotropic drugs }\end{array}$ & $\begin{array}{l}104(53.3) \\
65(33.3) \\
26(13.4)\end{array}$ & $\begin{array}{l}137(57.1) \\
71(29.6) \\
32(13.3)\end{array}$ & $\begin{array}{l}89(60.5) \\
37(25.2) \\
21(14.3)\end{array}$ & $\begin{array}{l}330(56.7) \\
173(29.7) \\
79(13.6)\end{array}$ & $\begin{array}{c}X^{2}=2.73 ; d f=4 \\
p=0.603\end{array}$ \\
\hline Family Apgar (median) & $10(0-10)$ & $10(0-10)$ & $9(0-13)$ & $10(0-13)$ & $\begin{array}{c}{ }^{*} X^{2}=1.82 ; d f=2 \\
p=0.398\end{array}$ \\
\hline $\begin{array}{l}\text { Coercive experiences during infancy } \\
\text { No } \\
\text { Yes }\end{array}$ & $\begin{array}{l}162(84.4) \\
30(15.6)\end{array}$ & $\begin{array}{l}196(83.1) \\
40(16.9)\end{array}$ & $\begin{array}{l}116(79.4) \\
30(20.6)\end{array}$ & $\begin{array}{l}474(82.6) \\
100(17.4)\end{array}$ & $\begin{array}{c}X^{2}=1.46 ; d f=2 \\
p=0.482\end{array}$ \\
\hline $\begin{array}{l}\text { Sexual abuse during infancy } \\
\text { No } \\
\text { Yes }\end{array}$ & $\begin{array}{c}184(96.3) \\
7(3.7)\end{array}$ & $\begin{array}{c}224(96.1) \\
9(3.9)\end{array}$ & $\begin{array}{c}142(97.3) \\
4(2.7)\end{array}$ & $\begin{array}{c}550(96.5) \\
20(3.5)\end{array}$ & $\begin{array}{c}X^{2}=0.35 ; d f=2 \\
p=0.837\end{array}$ \\
\hline ISSI Social Integration (median) & $14(6-26)$ & $14(5-26)$ & $13(5-26)$ & $14(5-26)$ & $X^{2} 2.94 d f=2 ; p=0.23$ \\
\hline ISSI Attachment (median) & $6(0-6)$ & $6(1-6)$ & $6(1-6)$ & $6(0-6)$ & ${ }^{*} X^{2} 0.877 d f=2 ; p=0.645$ \\
\hline Life events (median) & $2(0-13)$ & $2(0-14)$ & $2(0-13)$ & $2(0-14)$ & ${ }^{*} X^{2} 3.86 d f=2 ; p=0.145$ \\
\hline
\end{tabular}

Table 1: Socio-demographic and experiential characteristics of the sample. 
Citation: Balestrieri M, Isola M, Gangi F, Sbrojavacca R, PResT-ED (2016) Anxiety is Prevailing in Non-Cardiac Chest Pain Subjects, while Somatisation is Not A Comparative Study in the Emergency Department. J Depress Anxiety 5: 243. doi: 10.4172/2167-1044.1000243

Page 4 of 6

\begin{tabular}{|c|c|c|c|c|c|c|}
\hline & NCCP & CCP & WOCP & Total (\%) & Sign & $\begin{array}{c}\text { Comparison } \\
\text { U Mann-Whitney test (with Bonferroni } \\
\text { correction) }\end{array}$ \\
\hline Total & 193 & 238 & 140 & & & \\
\hline SCL-90 (median) & $0.92(0-2.58)$ & $1.0(0-2.97)$ & $0.42(0-1.75)$ & $0.83(0-2.97)$ & $\begin{array}{c}X^{2}=81.37 ; d f=2 \\
p=0.0001\end{array}$ & $\begin{array}{l}\text { NCCP vs. CCP: } p=0.56 \\
\text { NCCP vs. WOCP: } p<0.0001 \\
\text { CCP vs. WOCP: } p<0.0001\end{array}$ \\
\hline PCS-12 (median) & $48(14-74)$ & $43(11-64)$ & $51(20-66)$ & $48(11-74)$ & $\begin{array}{c}X^{2}=35.51 ; d f=2 \\
p=0.0001\end{array}$ & $\begin{array}{l}\text { NCCP vs. CCP: } p=0.0003 \\
\text { NCCP vs. WOCP: } p=0.09 \\
\text { CCP vs. WOCP: } p<0.0001\end{array}$ \\
\hline MCS-12 (median) & $47(1-68)$ & $45(21-70)$ & $47(19-69)$ & $47(1-70)$ & $\begin{array}{c}X^{2}=1.16 ; d f=2 \\
p=0.558\end{array}$ & NS \\
\hline $\begin{array}{c}\text { HADS Anxiety (No. and \%) } \\
\text { No } \\
\text { Yes }\end{array}$ & $\begin{array}{c}110(56.4 \%) \\
85(43.6 \%)\end{array}$ & $\begin{array}{c}160(66.7 \%) \\
80(33.3 \%)\end{array}$ & $\begin{array}{c}121(82.3 \%) \\
26(17.7 \%)\end{array}$ & $\begin{array}{l}391(67.2 \%) \\
191(32.8 \%)\end{array}$ & $X^{2} 25.56(p<0.0001)$ & $\begin{array}{l}\text { NCCP vs. CCP: } p=0.029 \\
\text { NCCP vs. WOCP: } p<0.0001 \\
\text { CCP vs. WOCP: } p=0.001\end{array}$ \\
\hline $\begin{array}{c}\text { HADS Depression (No. } \\
\text { and \%) } \\
\text { No } \\
\text { Yes }\end{array}$ & $\begin{array}{c}148(75.9 \%) \\
47(24.1 \%)\end{array}$ & $\begin{array}{c}183(76.2 \%) \\
57(23.8 \%)\end{array}$ & $\begin{array}{l}119(80.9) \\
28(19.1)\end{array}$ & $\begin{array}{l}450(77.3 \%) \\
132(22.7 \%)\end{array}$ & $X^{2} 1.49(p=0.475)$ & NS \\
\hline VAS (median) & $1(0-10)$ & $0.8(0-10)$ & $0.1(0-10)$ & $0.5(0-10)$ & $\begin{array}{c}{ }^{*} X^{2} 11.61 ; d f=2 \\
p=0.003\end{array}$ & $\begin{array}{l}\text { NCCP vs. CCP: } p=0.73 \\
\text { NCCP vs. WOCP: } p=0.0008 \\
\text { CCP vs. WOCP: } p=0.002\end{array}$ \\
\hline TAS 1 (median) & $15(7-33)$ & $13(7-33)$ & $12(3-35)$ & $13(3-35)$ & $\begin{array}{c}{ }^{*} X^{2} 13.81 ; d f=2 \\
p=0.001\end{array}$ & $\begin{array}{l}\text { NCCP vs. CCP: } p=0.18 \\
\text { NCCP vs. WOCP: } p=0.0006 \\
\text { CCP vs. WOCP: } p=0.15\end{array}$ \\
\hline TAS 2 (median) & $12(5-25)$ & $12(5-26)$ & $12(5-21)$ & $12(5-26)$ & $\begin{array}{c}X^{2} 0.78 ; d f=2 \\
p=0.675\end{array}$ & NS \\
\hline TAS 3 (median) & $20(8-33)$ & $19(8-35)$ & $17(8-34)$ & $19(8-35)$ & $\begin{array}{c}\mathrm{X}^{2} 11.05 \mathrm{df}=2 \\
\mathrm{p}=0.004\end{array}$ & $\begin{array}{l}\text { NCCP vs. CCP: } p=0.36 \\
\text { NCCP vs. WOCP: } p=0.002 \\
\text { CCP vs. WOCP: } p=0.18\end{array}$ \\
\hline TAS tot (median) & $47(23-78)$ & $45(24-80)$ & $42(20-75)$ & $45(20-80)$ & $\begin{array}{c}X^{2} 14.58 d f=2 \\
p=0.0007\end{array}$ & $\begin{array}{l}\text { NCCP vs. CCP: } p=0.30 \\
\text { NCCP vs. WOCP: } p=0.0003 \\
\text { CCP vs. WOCP: } p=0.11\end{array}$ \\
\hline
\end{tabular}

Table 2: Distribution of variables among groups and results of univariate analyses.

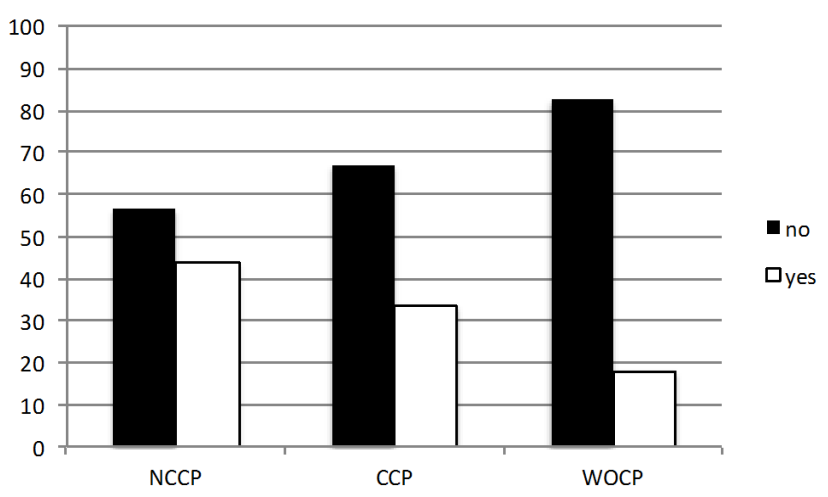

Figure 1: Distribution of percentages of HADS-anxiety scores across the three groups of subjects. (No = HADS-anxiety scores 0-7; Yes = HADS-anxiety scores $8+$ ).

different, even when adjusted for socio-demographic variables and BMI. The PCS-12 mean score of NCCP subjects was higher than that of CCP ( $B-2.31$; IC95\% -4.14 to -0.48) and lower than that of WOCP subjects ( 2.24 ; IC95\% $0.12-4.37)$.

\section{Discussion}

We found evidence of a specific profile of chest pain subjects (both NCCP and CCP) on several measures, as respect to WOCP subjects. In particular, we uncovered that NCCP subjects were more anxious than CCP subjects, and both were more anxious than WOCP subjects. If we refer to the review of Webster et al. [4], we found that only three studies compared anxiety in NCCP and CCP subjects, and all of them showed similar scores in the two groups [18-21]. On the other hand, a previous longitudinal study confirmed that HADS anxiety, but not HADS depression, was more elevated in NCCP subjects than in ischemic heart disease patients [22]. A possible explanation for these differences is that none of the three studies selected in the review used a psychiatric investigation to assess the presence of panic disorder. This is not trivial: for example, Srinivasan and Joseph [23] found that NCCP subjects were more likely to experience anxiety and depression if they also had co-morbid panic disorder. In our study, we excluded the patients with panic disorder in order to control for the possible interference of comorbidity with this psychiatric disorder.

More limited differences were found when exploring the somatisation construct. Both NCCP and CCP were more somatising than primary care patients, according to the SCL-90 somatization scale. As far as the TAS-20 profile is concerned, our results seem to indicate the presence of a greater difficulty in identifying feelings and an externally oriented thinking in NCCP subjects, in coherence with the psychosomatic construct of the TAS-20, even if the scores obtained were always below the range of scores (52-60 on the total) needed to assess the presence of a possible alexithymia. Possible references to the literature on this topic are the study of Dammen et al. [24], who did not find differences in the TAS-20 total score between NCCP and CCP subjects, and the study of Garcia-Campayo et al. [25], who on the contrary found that alexithymia was increased among the NCCP subjects as compared with coronary heart disease patients. In conclusion, we can suggest that according to our data NCCP subjects are a group of mild somatisers not completely distinct from CCP subjects. We need further confirms from other studies. 
An ancillary result of our study is that NCCP subjects presented a better physical health-related QoL than CCP subjects. Three studies analysed the QoL in the review of Webster et al. [4], showing that NCCP subjects have better QoL than CCP subjects, but worse than healthy controls. Although the latter result was not completely confirmed in our study, we can endorse the observation that even if chest pain impacts negatively on the physical component of QoL, NCCP subjects are less impaired probably because they have physical problem to a lesser degree than CCP subjects.

When we focus on the secondary hypotheses of our study, we must observe that traumatic or interpersonal risk factors were not able to characterise the three groups: neither the present (with dimensions such as attachment, social integration, family relations, life events), nor the past experiences (coercive methods and abuse) could be evocated as possible explanations of chest pain. Looking at the literature, OrthGomer [14] and Rosengren et al. [15] found that both attachment and social integration measured with ISSI instrument were low in subjects who suffered from a coronary heart disease. However, they did not analyse separately NCCP subjects. Moreover, Biggs et al. [18] found no significant differences in childhood adversities between NCCP and ischemic heart disease patients.

Consequently, we must reject our secondary hypotheses that traumatic experiences or interpersonal conflicts were associated with functional symptoms of chest pain. The literature on this topic is at the moment scarce, and more studies are needed to identify if specific experiences are related with non-cardiac chest pain.

\section{Conclusion}

In conclusion, our data seem to confirm that in the Emergency Department NCCP subjects show higher anxiety and a better physical QoL than patients who have a cardiac failure. Moreover, subjects with chest pain are more somatising than primary care patients, but only NCCP subjects show higher levels, albeit not pathologic, of alexithymia. Coherently with the lack of differences in somatisation between the two groups of chest pain patients, we did not find a specific risk of childhood adversity or altered familial/social interactions in NCCP subjects.

On the whole, it appears that anxiety defines more consistently than somatisation NCCP subjects and helps to differentiate them from patients with pain of cardiac origin. These conclusions have important consequences for the treatment. It is reassuring that anxiety, a clear psychopathologic dimension for which definite instruments of care (drugs and psychosocial treatments) are available, should be the major target of our intervention. On the other hand, less importance must be granted to somatisation, a less validated psychopathologic construct. When we refer to the latter, a broadly accepted notion is that pain emerges from psychological stress or from unresolved psychic conflicts. As a matter of fact, this belief remains largely untested, similarly to other stimulating models about the onset of pain complaints [26]. Our data give evidence that neither present nor past traumas can explain the pain experience and that a psychogenic nature of chest pain is improbable. Consequently, we are supported in the indication to consider and treat anxiety in chest pain subjects, while a complex investigation on the psychogenic nature of the pain symptoms might be not required. Of course, this does not imply that we do not need to explore at the individual level the history of the patients in search of psychosocial hints potentially related to the expression of chest pain. The role of a care manager in the Emergency department, as key health care collaborator able to enhance and support services to patients, may be useful [27].
This study has some limitations. The first one is that we used questionnaires to assess the response of the subjects. Even though we used also the MINI diagnostic interview to exclude the presence of panic disorder, the use of sole questionnaires may have altered the entity of reports of symptoms, quality of life or traumatic experiences. This could be particularly relevant if we consider the setting in which the study was carried out, characterised by an elevated level of emotional activation. On the other hand, a possible strength of the study is that we administered several psychometric instruments, all of which tested in other studies that could be used as comparison.

Another source of bias is that even if we used well-known questionnaires to explore the presence of potential familial/social interactions and stresses, we acknowledge that there may be other factors linked with chest pain that were not explored. Finally, a limitation of our analysis is that we could not explore if anxiety was the cause or the consequence of pain symptoms. Notwithstanding this, we must admit that chest pain is a distressing condition even when of non-cardiac origin. Therefore, in the Emergency Department the medical staff must carefully assess and treat the symptoms of anxiety of the subjects with non-cardiac chest pain, since this approach may contribute to lower the proportion of these subjects, who risk overburdening the health services with recurring requests of care.

\section{References}

1. Bass C, Mayou R (2002) Chest pain. BMJ 325: 588-591.

2. Kuijpers PM, Denollet J, Wellens HJ, Crijns HM, Honig A (2007) Noncardiac chest pain in the emergency department: The role of cardiac history, anxiety or depression or Type D personality. Eur J Cardiovasc Prev Rehabil 14: 273-279.

3. Lipowski ZJ (1988) Somatization: the concept and its clinical application. Am J Psychiatry 145: 1358-1368.

4. Webster R, Norman P, Goodacre S, Thompson A (2012) The prevalence and correlates of psychological outcomes in patients with acute non-cardiac chest pain: a systematic review. Emerg Med J 29: 267-273.

5. Crombez G, Beirens K, Van Damme S, Eccleston C, Fontaine J (2009) The unbearable lightness of somatisation: a systematic review of the concept of somatisation in empirical studies of pain. Pain 145: 31-35.

6. Sheehan DV, Lecrubier Y, Sheehan KH, Amorim P, Janavs J, et al. (1998) The Mini-International Neuropsychiatric Interview (M.I.N.I.): the development and validation of a structured diagnostic psychiatric interview for DSM-IV and ICD10. J Clin Psychiatry 59 Suppl 20: 22-33.

7. Faravelli C, Abrardi L, Bartolozzi D, Cecchi C, Cosci F, et al. (2004) The Sesto Fiorentino study: Background, methods and preliminary results. Lifetime prevalence of psychiatric disorders in an Italian community sample using clinical interviewers. Psychother Psychosom 73: 216-225.

8. Derogatis LR, Rickels K, Rock AF (1976) The SCL-90 and the MMPI: a step in the validation of a new self-report scale. Br J Psychiatry 128: 280-289.

9. Zigmond AS, Snaith RP (1983) The hospital anxiety and depression scale. Acta Psychiatr Scand 67: 361-370.

10. Ware J Jr, Kosinski M, Keller SD (1996) A 12-item short-form health survey: Construction of scales and preliminary tests of reliability and validity. Med Care 34: $220-233$

11. Mc Cormack HM, Horne DJ, Sheather S (1988) Clinical applications of visual analogue scales: a critical review. Psychol Med 18: 1007-1019.

12. Bagby RM, Parker JD, Taylor GJ (1994) The twenty-item Toronto Alexithymia Scale - I. Item selection and cross-validation of the factor structure. J Psychosom Res 38: 23-32.

13. Unden AL, Orth-Gomer K (1989) Development of a social support instrument for use in population surveys. Soc Sci Med 29: 1387-1392.

14. Orth-Gomer K, Rosengren A, Wilhelmsen L (1993) Lack of social support and incidence of coronary heart disease in middle-aged Swedish men Psychosomatic Medicine 55: 37-43. 
Citation: Balestrieri M, Isola M, Gangi F, Sbrojavacca R, PResT-ED (2016) Anxiety is Prevailing in Non-Cardiac Chest Pain Subjects, while Somatisation is Not A Comparative Study in the Emergency Department. J Depress Anxiety 5: 243. doi: 10.4172/2167-1044.1000243

15. Rosengren A, Wilhelmsen L, Orth-Gomer K (2004) Coronary disease in relation to social support and social class in Swedish men. A 15 year follow-up in the study of men born in 1933. Eur Heart J 25: 56-63.

16. Smilkstein G (1978) The family APGAR: A proposal for a family function test and its use by physicians. J Fam Prac 6: 1231-1239.

17. Holmes TH, Rahe RH (1967) The Social Readjustment Rating Scale. J Psychosom Res 11: 213-218.

18. Biggs AM, Aziz Q, Tomenson B, Creed F (2004) Effect of childhood adversity on health related quality of life in patients with upper abdominal or chest pain. Gut 53: 180-186.

19. Cenker E, Oktay C, Bacanli A, Gulen B, Koparan C, et al. (2010) Anxiety and depressive disorders in patients presenting with chest pain to the emergency department: a comparison between cardiac and non-cardiac origin. J Emerg Med 39: 144-150.

20. Eslick GD, Talley NJ (2008) Natural history and predictors of outcome for noncardiac chest pain: a prospective 4-year cohort study. Neuro Gastroentero Motil 20: 989e97.

21. Mayou R, Thompson D (2002) Treatment needs of patients admitted for acute chest pain. J Psychosom Res 53: 1177-1183.
22. Tew R, Guthrie EA, Creed FH, Cotter L, Kisely S, et al. (1995) A long-term follow-up study of patients with ischemic heart disease versus patients with non specific chest pain. J Psychosom Res 39: 977-985.

23. Srinivasan K, Joseph W (2004) A study of lifetime prevalence of anxiety and depressive disorders in patients presenting with chest pain to emergency medicine. Gen Hosp Psychiatry 26: 470-474.

24. Dammen T, Arnesen H, Ekeberg O, Friis S (2004) Psychological factors, pain attribution and medical morbidity in chest-pain patients with e without coronary artery disease. Gen Hosp Psych 26: 463-469.

25. García-Campayo J, Rosel F, Serrano P, Santed MA, Andrés E, et al. (2010) Different psychological profiles in non-cardiac chest pain and coronary artery disease: a controlled study. Rev Esp Cardiol 63: 357-361.

26. Gatchel RJ, Peng YB, Peters ML, Fuchs PN, Turk DC (2007) The biopsychosocial approach to chronic pain: scientific advances and future directions. Psychol Bull 133: 581-624.

27. Ciccone MM, Aquilino A, Cortese F, Scicchitano P, Sassara M, et al. (2010) Feasibility and effectiveness of a disease and care management model in the primary health care system for patients with heart failure and diabetes (Project Leonardo). Vasc Health Risk Manag 6: 297-305. 